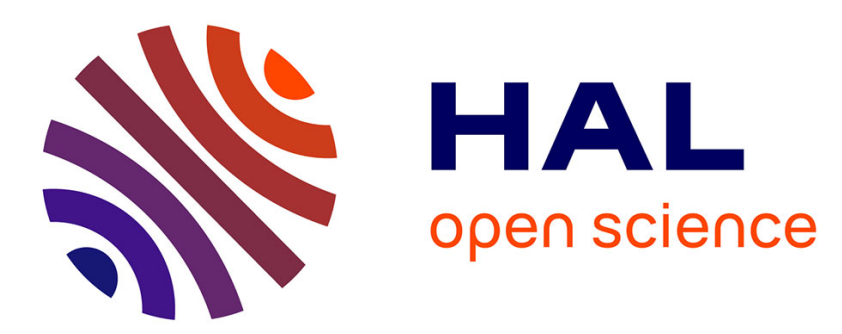

\title{
The effects of musical practice on structural plasticity: The dynamics of grey matter changes.
}

Mathilde Groussard, Fausto Viader, Brigitte Landeau, Béatrice Desgranges, Francis Eustache, Hervé Platel

\section{> To cite this version:}

Mathilde Groussard, Fausto Viader, Brigitte Landeau, Béatrice Desgranges, Francis Eustache, et al.. The effects of musical practice on structural plasticity: The dynamics of grey matter changes.. Brain and Cognition, 2014, 90, pp.174-80. 10.1016/j.bandc.2014.06.013 . inserm-01067834

\section{HAL Id: inserm-01067834 https://www.hal.inserm.fr/inserm-01067834}

Submitted on 24 Sep 2014

HAL is a multi-disciplinary open access archive for the deposit and dissemination of scientific research documents, whether they are published or not. The documents may come from teaching and research institutions in France or abroad, or from public or private research centers.
L'archive ouverte pluridisciplinaire HAL, est destinée au dépôt et à la diffusion de documents scientifiques de niveau recherche, publiés ou non, émanant des établissements d'enseignement et de recherche français ou étrangers, des laboratoires publics ou privés. 
The effects of musical practice on structural plasticity: The dynamics of grey matter changes

Running title: Dynamic effects of musical practice

\section{Mathilde Groussard ${ }^{1,2,3,4}$, Fausto Viader ${ }^{1,2,3,5}$, Brigitte Landeau ${ }^{1,2,3,4}$, Béatrice Desgranges $^{1,2,3,4}$, Francis Eustache $e^{1,2,3,4}$ and Hervé Platel ${ }^{1,2,3,4}$}

1 INSERM, U1077, Caen, France

2 Université de Caen Basse-Normandie, UMR-S1077, Caen, France

3 Ecole Pratique des Hautes Etudes, UMR-S1077, Caen, France

4 CHU de Caen, U1077, Caen, France

5 CHU de Caen, Service de Neurologie, Caen, France

\section{Correspondence and reprint requests:}

Mathilde Groussard, Inserm - EPHE-Université de Caen/Basse-Normandie-CHU de Caen, Unité U1077,

Laboratoire de Cyceron, Blvd Becquerel BP 5229, 14074 Caen cedex 5

Phone: +33 (0)2 314701 77; Fax: +33 (0)2 314701 06, e-mail: groussard@cyceron.fr

Any Conflict of Interest 


\begin{abstract}
Intensive training and the acquisition of expertise are known to bring about structural changes in the brain. Musical training is a particularly interesting model. Previous studies have reported structural brain modifications in the auditory, motor and visuospatial areas of musicians compared with nonmusicians. The main goal of the present study was to go one step further, by exploring the dynamic of those structural brain changes related to musical experience. To this end, we conducted a regression study on 44 nonmusicians and amateur musicians with 0-26 years of musical practice of a variety instruments. We sought first to highlight brain areas that increased with the duration of practice and secondly distinguish (thanks to an ANOVA analysis)brain areas that undergo grey matter changes after only limited years of musical practice from those that require longer practice before they exhibit changes. Results revealed that musical training results a greatergrey matter volumes in different brain areas for musicians. Changes appear gradually in the left hippocampus and right middle and superior frontal regions, but later also include the right insula and supplementary motor area and leftsuperior temporal, and posteriorcingulate areas. Given that all participants had the same age andthat we controlled for age and education level, these results cannot be ascribed to normal brain maturation. Instead, they support the notion that musical training could induce dynamic structural changes.
\end{abstract}

Keywords: music, training, plasticity, MRI, VBM 


\section{Introduction}

The effects of intensive training and expertise on brain structure have been observed in several areas (for reviews, see Draganski and May, 2008; May, 2011; Zatorre et al., 2012), including the taxi driver's hippocampus (Maguire et al. 2000), the juggler's midtemporal area (hMT/V5) and left posterior intraparietal sulcus (Boyke et al., 2008; Draganski et al., 2004), the basketball player's cerebellum (Park et al., 2009) andthe frontal and parietal areas of individuals who engage in physical exercise (Taubert et al., 2010).

It is now well established that musical training requires complex multimodal abilities, including somatosensory and memory processes, motor skills and emotion. Thus, musical expertise can be regarded as a relevant model for studying structural brain plasticity mechanisms (Wan and Schlaug, 2010). Skills acquired by musicians result not only in specific connections and interactions between different brain areas (Altenmuller, 2008, Fauvel et al. 2014), but also in the enlargement of brain regions involved in music-related processes such as auditory, motor and visuospatial abilities (Bermudez et al., 2009; Gaser and Schlaug, 2003; James et al. 2014;Luders et al., 2004; Schneider et al., 2002; Seung et al., 2005). In most studies, structural changes have been observed after onlya few months of intensive practice. For example, Hyde et al. (2009) showed that 15 months of instrumental musical training in childhood were enough to increase the volume of the auditory and motor cortices. Moreover, some authors have also shown a relationship between the age of onset of musical training and structural brain modifications particularly in the premotor cortex and corpus callosum (Bailey et al. 2014; Steele et al. 2013) for early-trained musicians (< age 7) suggesting a sensitive period of musical training effect. Nevertheless, these training-induced, regional structural brain changes do not occur solely during brain development, as they can be observed throughout the lifespan (Engvig et al., 2010). Nor are they restricted to specific cognitive 
demands (for a review, see Draganski and May, 2008), as they can concern many areas sustaining learning, memory, sensory or motor processes (see Fauvel et al. 2013 for review in musical training).Thus,some investigations have revealed that musical training can have structural and functional effects on regions not directly involved in sensori-motor processes of music practice, such as those that subtend working memory (Oechslin et al., 2012; Schulze et al., 2011) or long-term memory (Groussard et al., 2010a). In the latter study, a musical memory task revealed both functional and structural greater activation and grey matterin the left hippocampus of adult musicians compared to nonmusicians. Regarding results of our previous study, we would like togo one step further in the assessment of the relationship between the duration of musical expertise and the left hippocampus and generally in wholebrain grey matter changes.

The main goal of the present study is to analyze in what waystructural grey matter changes with increasing number of years ofmusical training. To this end, we conducted a regression study on grey matter volumes of 44 nonmusicians and amateur musicians with 0 26 years of musical practice of a variety instruments. We sought first to highlight brain areas that increased in volume with the duration of practice and secondly distinguish (thanks to an ANOVA analysis)brain areas that underwent grey matter changes after only limited years of musical practice from those that require longer practice before they exhibit changes. Actually, some neuroimaging studies on structural plasticity (for a review, see Jancke, 2009) have suggested that musical training initially induces structural changes in regions that are directly involved in music learning (i.e. auditory and motor cortices). But recently James et al. (2014) studied the expertise effect on grey matter changes comparing three groups: nonmusicians, amateur musicians and professional musicians and observed that grey matter areas related to higher-order cognitive function increase with musical practice. 
We therefore hypothesized that musical practice would have differential effects on the brain according to its duration, affecting first regions involved in motor and perceptual processes, to subsequently include regions involved in higher cognitive processes (i.e. executive functions, memory, and emotion).

\section{Methods}

\subsection{Participants}

Forty-four young volunteers $(26$ men, mean age $\pm S D: 23.75 \pm 3.43$ years, mean education level $\pm S D$ : $15.45 \pm 2.02$ years) with no history of neurological or psychiatric disease took part in this study. All participants were right-handed according to the Edinburgh Inventory (Oldfield, 1971), none of them reported having hearing deficits and none had perfect pitch. This study was approved by the regional ethics committee, and written informed consent was obtained from all the participants.

In order to study the progression of musical expertise from the verybeginning, eleven nonmusicianparticipants were included. They were classified as strictly nonmusicians, and met the following criteria: (1) none had ever taken part in musical performances or received music lessons (except for basic musical education at French high school, corresponding to 1 hour/week), (2) they were common listeners (i.e., not music lovers, who tend to listen to one specific type of music), and (3) they scored normally on a test of pitch perception. The remaining 33 participants were amateurmusicians that had been playing music several times a week (5 minimum to 10 hours maximum per week was our range of inclusion), for a time duration ranging from one to 26 years at the time of the study. We chose to select young adult participants in order to excludepossible effects of age on grey matter andto focus mainly on 
the effect of the duration of musical practice. Thus, in order to reveal the dynamicof grey matter changes, the musicians were divided into three groups according to the musical education phases and levels of trainings such as they are cut out in the musical academies in France (Table 1). Thus, the 11 musicians with 1-8 years' musical practice constituted the novice group. These novice musicians were in the process of acquiring basic musical skills (rhythm and music reading), which takes 8 years to be completed. The 11 musicians with 9-14 years' musical practice constituted the intermediate group. In this group, musicians were working on their musical training in preparation for the French final musical diploma. Finally, the 11 musicians with 15 or more years' musical practice constituted the expert musician group who had obtained their French final musical diploma('Certificat de fin d'études musicales'). Thus, within each group, musical proficiencies of our participants are pretty homogeneous. Moreover, we intentionally set up our groups of musicians by choosing various types of instrumental practice(violin, cello, guitar, flute, recorder, trumpet, clarinet and piano)in order to avoid the possible bias induced by a particular type of instrumental practice (in reference to the work of Sluming et al. 2002). Most of our musicians played more than one instrument. The distribution of the primary instrument played by the musicians of our three groups is the following one: 9 strings and 2 winds in novice musician group; 5 strings, 5 winds and 1 pianist in intermediate musician group; 1 string, 5 winds and 5 pianists in expert musician group. 


\begin{tabular}{|l|c|c|c|c|}
\hline & Nonmusicians & $\begin{array}{l}\text { Novice } \\
\text { musicians }\end{array}$ & $\begin{array}{l}\text { Intermediate } \\
\text { musicians }\end{array}$ & Expert musicians \\
\hline Female/Male & $5 \mathrm{~F} / 6 \mathrm{M}$ & $4 \mathrm{~F} / 7 \mathrm{M}$ & $6 \mathrm{~F} / 5 \mathrm{M}$ & $3 \mathrm{~F} / 8 \mathrm{M}$ \\
\hline $\begin{array}{l}\text { Age in years }( \pm \\
S D \text { and range) }\end{array}$ & $\begin{array}{c}25 \pm 3.41(21- \\
32)\end{array}$ & $\begin{array}{c}24.90 \pm 3.80(21- \\
32)\end{array}$ & $\begin{array}{c}21.09 \pm 0.94(20- \\
23)^{\mathrm{a}, \mathrm{b}}\end{array}$ & $24.18 \pm 3.54(21-$ \\
\hline $\begin{array}{l}\text { Education in } \\
\text { years }( \pm \boldsymbol{D} \text { and } \\
\text { range) }\end{array}$ & $\begin{array}{c}16.9 \pm 2.17 \\
(14-20)\end{array}$ & $\begin{array}{c}14.64 \pm 2.80(10- \\
19)^{\mathrm{a}}\end{array}$ & $\begin{array}{c}14.82 \pm 0.60(14- \\
16)\end{array}$ & $15.45 \pm 1.13(14-$ \\
\hline $\begin{array}{l}\text { Range of } \\
\text { musical } \\
\text { practice } \\
\text { (mean } \pm S D \text { ) }\end{array}$ & 0 & $1-8(4.6 \mathrm{yrs} \pm$ & $9-14(13.5 \mathrm{yrs} \pm$ & $17)$ \\
\hline $\begin{array}{l}\text { Age of onset of } \\
\text { training in } \\
\text { years }( \pm S D \text { and } \\
\text { range) }\end{array}$ & - & $20.27 \pm 5.33(14-$ & $7.45 \pm 0.82(6-9)$ & $6.63 \pm 1.36(5-9)$ \\
\hline
\end{tabular}

Table 1: Mean ( \pm standard deviation) demographic data for each group. For the statistical results of the post hoc 2-by-2 comparisons (Tukey's HSD) only significant differences at $p<.05$ are shown: ${ }^{\mathrm{a}}$ compared with nonmusician group, ${ }^{\mathrm{b}}$ compared with novice musician group.

\subsection{MRI Data Acquisition}

Each participant underwent an MRI examination at the CYCERON center (Caen, France) using the Philips (Eindhoven, The Netherlands) Achieva 3.0T scanner . T1-weighted structural images were acquired using a 3D fast field-echo sequence (3D-T1-FFE sagittal; TR $=20 \mathrm{~ms} ; \mathrm{TE}=4.6 \mathrm{~ms}$; flip angle $=20^{\circ} ; 170$ slices; slice thickness $=1 \mathrm{~mm}$; no gap; FOV $=$ $256 \times 256 \mathrm{~mm}^{2} ;$ matrix $=256 \times 256 ;$ in-plane resolution $=1 \times 1 \mathrm{~mm}^{2} ;$ acquisition time $=9.7$ $\min )$.

\subsection{Data preprocessing and statistical analysis}

\subsubsection{Demographic statistical analyses}


One-way ANOVA were run on the demographic data: age and level of education. Mean level of education differed significantly between the nonmusician $(16.9 \pm 2.17$ years $)$ and novice musician groups $(14.64 \pm 2.80$ years $), p<.05$; see Table 1$)$. Mean age differed significantly between the nonmusician $(25 \pm 3.41$ years $)$ and intermediate musician groups (21.09 \pm .94 years), and between the novice (24.90 \pm 3.80 years) and intermediate musician groups $(21.09 \pm .94$ years, $p<.05$; see Table 1$)$.Consequently, in all the statistical analyses, age and educational level were included as confounding variables.

We performed a Kruskal-Wallis one-way ANOVA in order to test gender distribution and no difference was observed between the four groups.

\subsubsection{Anatomical data preprocessing}

Imaging data preprocessing and analysis were performed using SPM12software (Wellcome Trust Center for Neuroimaging, London, UK) implemented in Matlab 7.4. Briefly, individual MRI data were spatially normalized to the Montreal Neurological Institute (MNI) template and segmented to isolate the grey matter partitions using the New Segment procedure in SPM12 and the DARTEL toolbox (Ashburner, 2007). Finally, the resulting modulated images (i.e. grey matter (GM) volume), which allow detection of relatively subtle changes in tissue contrasts were smoothed with an 8-mm FWHM isotropic Gaussian kernel.The resulting preprocessed images were masked so as to include only voxels considered as GM in the statistical analyses.

We also obtained the individual total volume of GM, white matter (WM) and cerebrospinal fluid (CSF) that we used to calculated the individual total intracranial volume 
(TIV) by summing the volume of the three compartments. In the imaging analyses described below, the TIV was used as a covariate to correct for brain volume difference.

\subsubsection{Imaging statistical analyses}

\subsubsection{Brain Regions Modified by Musical Practice.}

First, we performed a regression analysis for the whole sample (44 participants) between the whole-brain GM volumes and the duration of musical practice, controlling for age, educational level and TIV, in order to first, locate the areas where grey matter volumesincreased with the duration of musical practice and second, highlight regions where grey matter volumes decreased with the duration of musical practice.

\subsubsection{Dynamics of Brain Regions Modified by years of Musical Training}

Second, to highlight the possible dynamics of grey matter volume modifications related to duration of musical practice,we divided the participants into four groups (Table 1) according to the duration of their musical training and extracted (using a fMRI_ROI toolbox developed in our lab) the grey matter volumes of the areas that were significant (at $\mathrm{p}<.001$ uncorrectedfor multiple comparisons and cluster size $\mathrm{k}>110$ in the regression analysis. Using Statistica softwarewe performed one-way ANOVAs(controlling for age, educational level and TIV) for each region and conduct post hoc comparisons (Tukey's HSD) of grey matter volumes between the four groups (nonmusicians, and novice, intermediate and expert musicians). For the statistical results of the post hoc 2-by-2 comparisons (Tukey's HSD) we discussed significant differences at $\mathrm{p}<0.05$. 


\subsubsection{Influence of Age of Onset of musical training}

Finally, to highlight brain areas modified by early and late musical training (before and after age 7 of onset), we performed as a complementary analysis a two-sample t-test (at p < .001 uncorrected for multiple comparisons and cluster size $\mathrm{k}>110$ ) on GM images of the 15 musicians who began music before age 7 compared to 18 musicians who began music later (after age 7). To control for duration of musical practice, number of years of practice was included as covariate, and we also set age, educational level and TIV as covariates.

\section{Results}

\subsection{Brain Regions Modified by Musical Practice}

Positive correlations between GM volume and the duration of musical practice were found in the left hippocampus,posterior cingulate gyrus and superior temporal cortex, and in the right insular, middle and superior frontal cortices, and supplementary motor area Figure 1 and Table 1). These same areas were foundafter controlling for gender, by including this parameter as a nuisance variable in the model (data not shown). No brain area exhibited a negative correlation between GMvolumeand the duration of musical practice.

\subsection{Dynamics of Brain Regions Modified by years of Musical Training}

Except for the right insula $(\mathrm{F}(3,37)=2.25, \mathrm{p}=0.09)$, all these areas present a significant main effect of musical expertise, aftercontrolling for age,educational leveland TIV: the left hippocampus $(\mathrm{F}(3,37)=5.25, \mathrm{p}=0.003)$, posterior cingulate $(\mathrm{F}(3,37)=3.56, \mathrm{p}=0.023)$ and superior temporal cortex $(\mathrm{F}(3,37)=3.71, \mathrm{p}=0.019)$, and the right middle and superior frontal cortices $(\mathrm{F}(3,37)=6.39, \mathrm{p}=0.001)$, and supplementary motor area $(\mathrm{F}(3,37)=5.78, \mathrm{p}=0.002)$.Post hoc between-group comparisons conducted on the GM volume of the brain regions found in the previous analysis suggested distinct patterns of training-induced structural changes (Fig 1. 
Statistical results of the post hoc 2-by-2 comparisons (Tukey's HSD) revealed, for the left hippocampus: significant differences between the nonmusicians and novice $(p=0.024)$, intermediate $(\mathrm{p}=0.0007)$ and expert musician $(\mathrm{p}=0.0001)$ groups and between the novice musicians and expert musicians $(\mathrm{p}=0.015)$; for the left posterior cingulate cortex: significant differences between the nonmusicians and the expert musicians $(\mathrm{p}=0.0002)$ and between the intermediate musicians and the expert musicians $(\mathrm{p}=0.036)$; for the left superior temporal gyrus: significant differences between nonmusicians and the expert musicians $(p=0.003)$ and between the intermediate musicians and the expert musicians $(\mathrm{p}=0.032)$; for the right middle and superior frontal cortices: significant differences between the nonmusicians and intermediate $(\mathrm{p}=0.027)$ and expert musician $(\mathrm{p}=0.0001)$ groups and between the expert musicians and the novice $(\mathrm{p}=0.009)$ and intermediate musicians $(\mathrm{p}=0.036)$; and for the supplementary motor area the only significant difference was observed between the nonmusicians and the expert musicians ( $\mathrm{p}=0.04)$ ( Fig. 1).

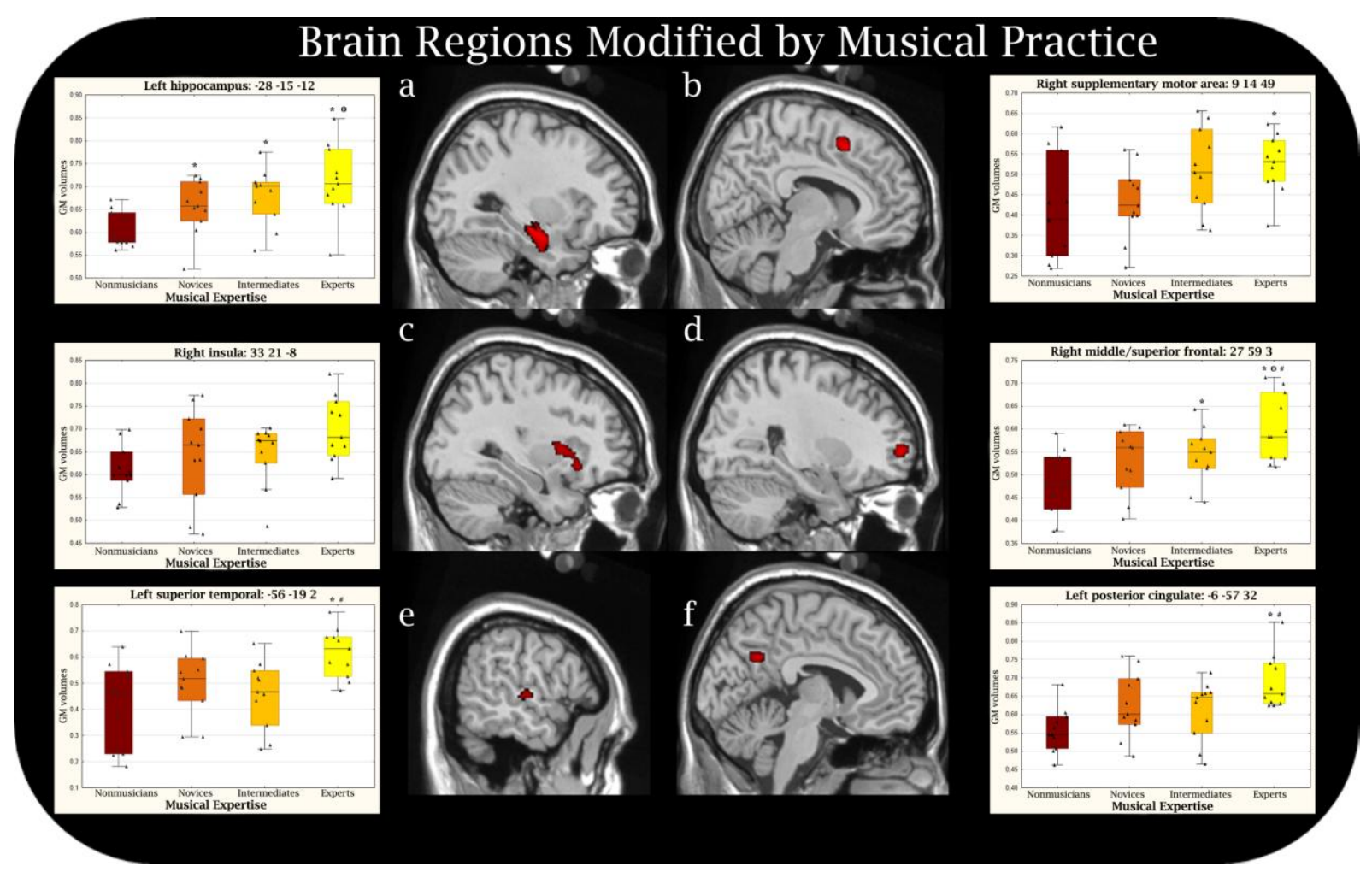


Fig 1:Brain areas in which grey matter density changed with musical expertise. Results displayed the brain areas with significant positive correlationat $p<.001$ uncorrectedfor multiple comparisons and cluster size $\mathrm{k}>110$ between the duration of musical practice and GM volumes (controlling for age, educational level and TIV) and boxplot representations of GM volumes of (a) the left hippocampus, (b) right supplementary area, (c) right insula, (d) right superior and middle frontal cortex, (e) left superior temporal cortex and (f) left posterior cingulate cortex for each group. Box plots represent data of each group with quartiles (upper values $75 \%$, median, and lower values $25 \%$ ). The whiskers show range of the data and blobs raw values. For statistical results of the post hoc 2-by-2 comparisons (Tukey's HSD) only significant differences are shown: * compared with the nonmusician group, o compared with the novice musician group and \# compared with the intermediate musician group.

\begin{tabular}{|l|c|ccc|c|}
\hline \multicolumn{1}{|c|}{ Anatomical location } & $\begin{array}{c}\text { Cluster size } \\
\text { (in voxels) }\end{array}$ & $\mathbf{x}$ & $\mathbf{y}$ & $\mathbf{z}$ & $\boldsymbol{Z}$ score \\
\hline Lefthippocampus & 434 & -28 & -15 & -12 & 4.77 \\
$\begin{array}{l}\text { Right supplementarymotor } \\
\text { area }\end{array}$ & 114 & 9 & 14 & 49 & 4.43 \\
$\begin{array}{l}\text { Right superior and middle } \\
\text { frontal cortex }\end{array}$ & 211 & 27 & 59 & 3 & 4.22 \\
Leftposteriorcingulate cortex & 165 & -6 & -57 & 32 & 4.02 \\
Right insula & 177 & 33 & 21 & -8 & 3.70 \\
Leftsuperior temporal & 122 & -56 & -19 & 2 & 3.47 \\
\hline
\end{tabular}

Table 2:Brain areas in which GM volume changed with musical expertise.Location and MNI x, y, z coordinates (in mm) of peaks of significant grey matter density increases revealed by the analysis of variance with age, years of education and TIV as covariates. In all the areas listed, changes in grey matter volume are statistically significant at the $p<.001$ uncorrected level for multiple comparisons and cluster size $\mathrm{k}>110$. 


\subsection{Influence of Age of Onset of musical training}

The two-sample t-test performed on 15 musicians who began music before age 7 compared to 18 musicians who started music later (after age 7), revealed no significant GM difference, and neither didthe reverse comparison. Thus, controlling for the duration of musical practice, nobrain area seemed to be specifically influenced by the age of onset of musical training.

\section{Discussion}

Consistent with the evidence that musical training can bring about neural plasticity in the brain (for reviews, see Stewart, 2008; Wan and Schlaug, 2010), the results of the present study showed only significant positive correlations between the duration of musical practice and changes in grey matter volumes in specific brain regions that have already been found to be sensitive to musical training or expertise (Bermudez et al., 2009; Groussard et al., 2010a; Hutchinson et al., 2003; Hyde et al., 2009;James et al. 2014;Schneider et al., 2002).The comparison of subjects with different levels of musical expertise enabled us to extend our understanding of brain plasticity in musicians, by allowing us to analyze different grey matter changes within each brain region in the course of musical training.

\subsection{Different Structural Changes across Musical Practice}

Our analyses indicated that the grey matter modifications associated with musical practicediffer according to brain regions (Fig 1). These changes appear to be already noticeable in novice musicians and were greater in the intermediate and expert musician groupin the right middle and superior frontal regions andleft hippocampus, whereas structural modifications in the left superior temporal, posterior cingulateand right supplementary motor 
areas seem to beless linear andappear only after several years of musical practice. Given that we controlled for age and education level, these results cannot be ascribed to normal cerebral maturation. So,these findings suggest that experience-dependent shifts within cognitive processes take place during musical training (Bermudez et al., 2009; Hyde et al., 2009).

\subsubsection{Leftsuperior temporal gyrus}

The left superior temporal gyrus is the structure where grey matter density greater the most $(50 \%)$ in expert musicians versus nonmusicians.Previous studies observed an increase of GM in the left superior temporal lobes in musicians (Schneider et al. 2002; GaseretSchlaug 2003; James et al. 2014) compared to nonmusicians suggesting a direct effect of musical practice on this area. Moreover, functional imaging studies have revealed that bothsuperior temporal areaswere involved in the processing of melody (Bengtsson and Ullen, 2006) and the left one in musical semantic memory (Groussard et al.2010b).We thus can hypothesize that throughout their training, musicians gradually develop the ability to decode the perceptual features of tunes (melody) and to memorize these features, in order to obtain a unique representation of each musical encounter. Moreover, previous research has suggested that the temporal structure is central to the recognition of familiar melodies. This brain area is thought to sustain the musical lexicon and could be involved in perceptual musical memories (Peretz et al., 2009). Given that the musical lexicon is gradually enriched through training and through listening to tunes, our results suggest that the grey matter differences in the left temporal area can be attributed to musical expertise.

\subsubsection{Left posterior cingulate cortex}


We observed a $23.5 \%$ enlargement in grey matter volume in the left posterior cingulate cortex of the expert musicians, compared with the nonmusicians. Hyde et al. (2009) previously observed a grey matter increase in the posterior cingulate cortex in children after 15 month of musical training and interpreted this fact as a consequence of integration of sensory information (visual) and emotional contentoccurring during the learning to read musical notation. Moreover, in musical memory studies, this area appears to be activated during familiarity tasks featuring well-known songs (Groussard et al., 2010b;Satoh et al., 2006) and could underlie autobiographical memories associated with musical excerpts (Ford et al., 2011).

\subsubsection{Right insular cortex}

We observed an enlargement of grey matter in the insula cortex with the duration of musical practice but no clear pattern of modification appears regarding the level of musical expertise, nevertheless we could observe $14.6 \%$ difference between the expert musicians and the nonmusicians. This area is thought to reflect the emotional aspects of music processing (Koelsch et al., 2005; Koelsch, 2010). A positive correlation has been observed between the activation of the insula and the intensity of the thrills induced in musicians by favorite pieces of classical music (Blood and Zatorre, 2001). We can assume that, musicians hone not just their technical prowess but also their emotional sensitivity to music. In the course of their musical experience, musicians develop the ability (their sensitivity) to perceive the emotional content inherent to different pieces of music and, in turn, the ability to communicate that emotion to their audience.

\subsubsection{Right supplementary motor area}


An increase in grey matter of the right supplementary motor area only seemsto appear after 15 or more years of musical practice, amounting to $26 \%$ between the expert musicians and the nonmusicians. This structure,together with the premotor cortex, had previously shown a greater GM volume in musicians vs. nonmusicians(Gaser and Schlaug 2003).This cerebral area was also observed in musical studies focusing on the processing of sequential temporal structures in passive rhythm perception (Bengtsson et al. 2009). fMRIstudies, revealed that in pianists the supplementary motor area could be involved in both pitch and timing repetition during listening and performance tasks (Brown et al. 2013), as well as in the rhythmic and melodic musical improvisation (Manzano\&Ullén, 2012) confirming its probable implication during musical training. On the other hand, some studies suggested that when musicians reach a professional status, the activity of motor structures decrease, which is likely to reflect motor automatizationor specialization (Gaser\&Schlaug 2003, James et al. 2014).

\subsubsection{Right superior and middle frontal gyri}

Our study shows that, in the right superior and middle frontal gyri, grey matter volumes seems to undergo a gradual increase, to reach a $25 \%$ difference between the expert musicians and the nonmusicians. These structures have already been found in musical studies, and appear engaged in musical episodic retrieval (Platel et al. 2003) and also recruited by selfreferential processes associated with music (Zatorre et al., 2010), that are high-level cognitive processes developed with musical experience. One recent study explored brain structures that are activated when musicians play in an ensemble, and suggested that the cognitive empathy needed to take account of the other musicians and to play a piece of music together accurately is largely mediated by frontal areas BA 10/11 (Babiloni et al., 2012). Thus, we can hypothesize that the gradual modification in the right superior and middle frontal cortex with the musical expertise appears because playing in a music ensemble requires mastery of one's 
instrument synchronized with the other players, which is acquired progressively with the years of practice.

\subsubsection{Left anterior hippocampus}

We observed a gradual increase between duration of musical practice and grey matter volumes in the anterior part of the left hippocampus, suggesting a specific impact of musical practice on this area. This difference reached $17.8 \%$ with a greater grey matter volume for the expert musicians, compared with the nonmusicians.

Hippocampal grey matter changes were already noticeable in the novice vs. nonmusicians. This structure is closely involved in context-dependent episodic or autobiographical memory (Burgess et al., 2002; Viard et al., 2007), suggesting that musicians construct specific memories relating to their musical experiences (e.g., a particular melody played during a specific concert). Thus, musicians' memories of music may be more detailed, vivid and emotional than those of nonmusicians (Groussard et al., 2010a). Using grey matter volume analysis, Rajah et al. (2010) observed the involvement of the anterior part of the hippocampus in binding spatial and temporal contextual details with item information during encoding and/or retrieval-an ability that is also required in musical practice (e.g., reading a music score). Given the high intensity of auditory-visual encoding processes that characterizes music learning, our findings fit well with this assumption.

Moreover, training-related neurogenesis has been found in the hippocampi of both animals and humans (Eriksson et al., 1998; Kempermann et al., 2002; Fotuhi et al. 2012 for review). In humans, modifications in hippocampal grey matter have been observed such as in London taxi drivers (Maguire et al., 2000) and medical students taking examinations 
(Draganski et al., 2006), as well as in older people following a period of intense learning (Boyke et al., 2008), suggesting the biological engraving of new learning. These observations, taken together with the present results, suggest that musical practice could influence neurogenesis in the left hippocampus, whatever the level of musical expertise or the age of onset,and could possibly reflect an increasein memory faculties.

\section{Profits and limits}

We carried out a global regression analysis in order to give an account of the effect of years of musical practice on GM volume. Given that we controlled for age and education level, and that all participants were young adults, ourresults cannot be ascribed to normal cerebral maturation or aging effect. In addition, the major interest of including a group of strictly nonmusiciansin our experimental sample is precisely to be able to reveal early GM modifications related to the musical practice. Then, the ANOVA carried out makes it possible to show the contribution of each group in the GM modifications, and allows us to analyze grey matter changes within each brain region in relation with the number of yearsof musical training.One can however wonder whether the results of the regression analysis could mainly reflect the contribution of the nonmusicians group. We thus carried out the regression analysis (data not shown) on the 3 groups of musicians only, with TIV, Age,and Education level as covariates, and we obtainedmost of the cerebral areas already found in our previous analysis (that included nonmusicians). Unlike James et al. (2014) we did not observe any decrease in sensorimotor areas,possibly because our study included amateur musicians. All themusician in our study (from "novice' to "expert") practiced 5-10 hper week (selection criteria) whereasin the study of James et al. (2014) musicians who were professional pianists practicedmore than 10 hours. It is thus possible that the decrease in sensorimotor areas GM density needs a more intensive musical practice than that of non-professional musicians. 
While most studies included only pianists, we deliberately decidednot to select our subjects on instrumental criteria (in reference to the work of Sluming et al. 2002) so as to limit the influence of a particular type of instrumental practice. The global repartition of instrumental practice is quite homogeneous in our sample of musicians (see 2.1 Participants), and most of our musician subjects, after learninga primary instrument had finally becomemulti-instrumentists. Our results thus reflect the cerebral effects of musical rather than instrumental training. However, it would be definitely interesting to have a larger sample of different kind of instrumentalists in order to learn whether particular instrumental practices differently modify GM volume during time.

Concerning the possible effect of gender repartition in our results, we carried out a Kruskall-Wallis ANOVA, which does not show any significant difference between male and female repartition in our experimental group. We also checked that the results of the main correlation between musical practice and GM volume were not modified by including gender as covariate in our analysis (data not shown). However, we did a comparison (two-sample) between men and women participants by putting in covariate the number of years of practice. We found a significant greaterGM volume in men in motor areas: the cerebellum and the paracentral lobule (data not shown), while the opposite comparison did not show any such significant difference in women vs. men. As some authors have already observed (Hutchinson et al. 2003), if we compare men and women populations with the duration of musical practice as a covariate, grey matter differences are found only in men in motor area:cerebellum and paracentral lobule. The reason of such effect is unknown and needed future studies.

Clearly, the cross-sectional design of this study limits the interpretations regarding the dynamics of grey matter modifications with duration of musical practice. These could be only confirmed with longitudinal studies carried out in nonmusicians who would learn a musical 
instrument over a long period of time (e.g.15 or more years of musical practice), which is quite a challenging task in a research context.Nevertheless, our results do provide substantial evidencethat localized, structural modifications and adaptations occur in response to the longterm musical training and acquisition of skills specifically needed to play an instrument.Asthe two-sample t-test performed on 15 musicians who began music before age 7 compared to 18 musicians who started music later (after age 7), revealed no significant GM difference (as the reverse comparison), our results are likely to be explained by the number of years of musical practice rather than to reflect the influence of the onset of musical education taking place at a “sensitive" period of life (White et al. 2013). In other word, although some authors observed an effect of early-training music (for example, Bailey et al. 2014) our data suggested that even if musical training is begin after age of 7 , musical practice could also modified structural brain. Finally, it is difficult to isolate from the structural brain modifications observed, the respective impact of the age of onset and duration of musical practice, but these two variables have undoubtedly an influence and are probably additional.

\section{Conclusion}

The present findings illustrate the dynamics of structural brain changes related to musical practice. While neural plasticity occurs in some regions (left hippocampus and right middle and superior frontal), as soon as an individual engages in music learning, grey matter modifications in other brain areas (left posterior cingulated cortex, superior temporal areas and right supplementary motor area and insula cortex) require several years of practice. These differential dynamics of structural neuroplasticity according to brain regions can be attributed to two nonexclusive mechanisms. First, these brain regions may differ in terms of their intrinsic plastic properties (e.g., the hippocampus and its mechanism of neurogenesis). 
Second, the differential dynamics of change may reflect the involvement of different cognitive functions at different stages in music learning: initial improvements in motor, visual and perceptual skills and the progressive enhancement of the higher-level cognitive processes, such as semantic or episodic memory, meta-representation (emotional interpretation and musical expressiveness) and executive functions that are essential for playing in a music ensemble.

Further investigations are nowrequired to determine whether, from a more clinical perspective, musical practice could increase the so-called cognitive reserve in healthy aging and, perhaps, delay the emergence of cognitive decline in older people (Verghese et al., 2003).

\section{Acknowledgements}

We would like to thank all the members of the INSERM U1077 team, the staff at the Cyceron center for their help with data acquisition, Anne-Lise Pitel for providing such helpful comments and Elizabeth Portier for reviewing the English style. This study was supported by a grant from the Caissed'EpargneNormandie foundation. 


\section{References}

Altenmüller, E. 2008. Neurology of musical performance. Clinical Medicine. 8, 410-413

Ashburner, J. 2007. A fast diffeomorphic image registration algorithm. Neuroimage. 38, 95113

Babiloni, C., Buffo, P., Vecchio, F., Marzano, N., Del Percio, C., Spada, D., Rossi, S., Bruni; I., Rossini, P.M., Perani, D. 2012 Brains "in concert": frontal oscillatory alpha rhythms and empathy in professional musicians. Neuroimage.60,105-116

Bailey, J.A., Zatorre, R., Penhune V.B., 2014. Early musical training is linked to gray matter structure in the ventral premotor cortex and auditory-motor rhythm synchronization performance. J Cog Neurosci. 26,755-767

Bengtsson, S.L., Ullén, F. 2006. Dissociation between melodic and rhythmic processing during piano performance from musical scores. Neuroimage.30,272-284

Bengtsson, S.L., Ullén F., Ehrsson, H.H., Hashimoto T., Kito, T., Naito, E., Forssberg, H., Sadato, N. 2009.Listenning to rhythms activates motor and premotor cortices. Cortex. 45, 62-71.

Bermudez, P., Lerch, J.P., Evans, A.C., Zatorre, R.J. 2009.Neuroanatomical correlates of musicianship as revealed by cortical thickness and voxel-based morphometry.Cereb Cortex. 19,1583-1596

Blood, A.J., Zatorre, R.J. 2001. Intensely pleasurable responses to music correlate with activity in brain regions implicated in reward and emotion. PNAS.98, 11818-11823

Boyke, J., Driemeyer, J., Gaser, C., Büchel, C., May, A., 2008. Training-induced brain structure changes in the elderly.J Neurosci. 28,7031-7035

Brown, R.M., Chen, J.L. Hollinger, A.,Penhune, V.B., Palmer, C., Zatorre, R.J. 2013.Repetition suppression in auditory-motor regions to pitch and temporal structure in music.J CognNeurosci. 25, 313-328.

Burgess, N., Maguire, E.A., O'Keefe, J., 2002. The human hippocampus and spatial and episodic memory. Neuron.35, 625-641

Draganski, B., May, A., 2008. Training-induced structural changes in the adult human brain.Behav Brain Res.192,137-142

Draganski, B., Gaser, C., Kempermann, G., Kuhn, H.G., Winkler, J., Büchel, C., May, A., 2006. Temporal and spatial dynamics of brain structure changes during extensive learning.J Neurosci. 26,6314-6317

Draganski, B., Gaser, C., Busch, V., Schuierer, G., Bogdahn, U., May, A., 2004. Neuroplasticity: changes in grey matter induced by training. Nature. 427,311-312 
Engvig, A., Fjell, A.M., Westlye, L.T., Moberget, T., Sundseth, Ø., Larsen, V.A., Walhovd, K.B., 2010. Effects of memory training on cortical thickness in the elderly. Neuroimage.52, 1667-1676

Eriksson, P.S., Perfilieva, E., Björk-Eriksson, T., Alborn, A.M., Nordborg, C., Peterson, D.A., Gage, F.H., 1998. Neurogenesis in the adult human hippocampus. Nat Med.4, 1313-1317

Fauvel, B., Groussard, M., Eustache, F.,Desgranges, B., Platel, H. 2013. Neural implementation of musical expertise and cognitive transfers: could they be promising in the framework of normal cognitive aging? Front. Hum. Neurosci.7:693 doi: 10.3389/fnhum.2013.00693

Fauvel, B., Groussard, M., Chételat G., Fouquet M., Landeau, B., Eustache, F., Desgranges, B., Platel, H.2014. Morphological brain plasticity induced by musical expertise is accompanied by modulation of functional connectivity at rest. Neuroimage. 90,179-188

Ford, J.H., Addis, D.R., Giovanello, K.S., 2011. Differential neural activity during search of specific and general autobiographical memories elicited by musical cues. Neuropsychologia.49,2514-2526

Fotuhi, M., Do, D., Jack, C., 2012. Modifiable factors that alter the size of hippocampus with ageing. Nat. Rev. Neurol. 8, 189-202

Gaser, C., Schlaug, G., 2003. Brain structures differ between musicians and non-musicians. J Neurosci. 23,9240-5

Groussard, M., La Joie, R., Rauchs, G., Landeau, B., Chételat, G., Viader, F., Desgranges, B., Eustache, F., Platel, H., 2010a. When music and long-term memory interact: effects of musical expertise on functional and structural plasticity in the hippocampus. PLoS ONE5:e13225

Groussard, M., Rauchs, G., Landeau, B., Viader, F., Desgranges, B., Eustache, F., Platel, H., 2010b. The neural substrates of musical memory revealed by fMRI and two semantic tasks. Neuroimage. 53,1301-1309

Hutchinson, S., Lee, L.H-L., Gaab, N., Schlaug, G., 2003. Cerebellar volume of musicians. Cereb Cortex. 13, 943-949

Hyde, K.L., Lerch, J., Norton, A., Forgeard, M., Winner, E., Evans, A.C., Schlaug, G., 2009. Musical training shapes structural brain development. J Neurosci. 29, 3019-3025

James, C.E., Oechslin, M.S., Van De Ville, D., Hauert, C.-A., Descloux, C., and Lazyras, F. 2014. Musical training yields opposite effects on grey matter density in cognitive versus sensorimotor networks. Brain Struct. Funct. 219,353-66doi:10.1007/s00429-013-0504-z

Jancke, L., 2009. The plastic human brain. Restor Neurol Neuros. 27, 521-538

Kempermann, G., Gast, D., Gage, F.H., 2002. Neuroplasticity in old age: sustained fivefold induction of hippocampal neurogenesis by long-term environmental enrichment.Ann Neurol.52, 135-143 
Koelsch, S., 2010. Towards a neural basis of music-evoked emotions.Trends Cogn Sci.14 ,131-137

Koelsch, S., Fritz, T., Schulze, K., Alsop, D., Schlaug, G., 2005. Adults and children processing music: an fMRI study. Neuroimage.25, 1068-76

Luders, E., Gaser, C., Jancke, L., Schlaug, G., 2004.A voxel-based approach to gray matter asymmetries. Neuroimage.22, 656-64

Maguire, E.A., Gadian, D.G., Johnsrude, I.S., Good, C.D., Ashburner, J., Frackowiak, R.S., Frith, C.D., 2000. Navigation-related structural change in the hippocampi of taxi drivers. PNAS. 97, 4398-4403

Manzano, O., Ullén, F., 2012.Activation and connectivity patterns of presupplementary and dorsal premotor areas during free improvisation of melodies and rythms. NeuroImage, 63, 272-280

May, A., 2010. Experience-dependent structural plasticity in the adult human brain. Trends Cogn Sci. 15, 475-482

Oechslin, M.S., Van De Ville, D., Lazeyras, F., James, J.E. 2012. Degree of musical expertise modulates higher order brain functioning. Cerebral Cortex. doi: 10.1093/cercor/bhs206.

Oldfield, R.C, 1971. The assessment and analysis of handedness: the Edinburgh inventory. Neuropsychologia. 9, 97-113.

Park, I.S., Lee, K.J., Han, J.W., Lee, N.J., Lee, W.T., Park, K.A., Rhyu, I.J., 2009.Experiencedependent plasticity of cerebellar vermis in basketball players. Cerebellum. 8, 334-339

Peretz, I., Gosselin, N., Belin, P., Zatorre, R.J., Plailly, J., Tillmann, B., 2009. Music lexical networks: the cortical organization of music recognition. NYAS. 1169, 256-65

Platel, H., Baron, J-C., Desgranges, B., Bernard, F., Eustache, F., 2003. Semantic and episodic memory of music are subserved by distinct neural networks. Neuroimage. 20, 244256

Rajah, M.N., Kromas, M., Han, J.E., Pruessner, J.C., 2010. Group differences in anterior hippocampal volume and in the retrieval of spatial and temporal context memory in healthy young versus older adults. Neuropsychologia.48, 4020-4030

Satoh, M., Takeda, K., Nagata, K., Shimosegawa, E., Kuzuhara, S.. 2006. Positron-emission tomography of brain regions activated by recognition of familiar music. Am J Neuroradiol. 27, 101-106

Schneider, P., Scherg, M., Dosch, H.G., Specht, H.J., Gutschalk, A., Rupp, A., 2002. Morphology of Heschl's gyrus reflects enhanced activation in the auditory cortex of musicians. Nat Neurosci.5, 688-694

Schulze, K., Mueller, K., Koelsch, S., 2011. Neural correlates of strategy use during auditory working memory in musicians and non-musicians. Eur J Neurosci.33, 189-196 
Seung, Y., Kyong, J-S., Woo, S-H., Lee, B-T., Lee, K-M., 2005. Brain activation during music listening in individuals with or without prior music training. Neurosci Res. 52, 323329

Sluming, V., Barrick, T., Howard, M., Cezayirli, E., Mayes, A., Roberts, N., 2002.Voxelbased morphometry reveals increased gray matter density in Broca's area in male symphony orchestra musicians. Neuroimage,17,1613-22

Steele, C.J, Bailey, J.A., Zatorre, R.J., Penhune, V.B., 2013. Early musical training and white-matter plasticity in the corpus callosum: Evidence for a sensitive period. J Neurosci, $33,1282-1290$

Stewart, L., 2008. Do musicians have different brains?Clinical Medicine.8,304-308

Taubert, M., Draganski, B., Anwander, A., Müller, K., Horstmann, A., Villringer, A., Ragert, P., 2010. Dynamic properties of human brain structure: learning-related changes in cortical areas and associated fiber connections.J Neurosci.30, 11670-11677

Verghese, J., Lipton, R.B., Katz, M.J., Hall, C.B., Derby, C.A., Kuslansky, G., Ambrose, A.F., Sliwinski, M., Buschke, H., 2003. Leisure activities and the risk of dementia in the elderly.N Engl J Med. 348, 2508-2516

Viard, A., Piolino, P., Desgranges, B., Chételat. G., Lebreton, K., Landeau, B., Young, A., De la Sayette, V., Eustache, F., 2007. Hippocampal activation for autobiographical memories over the entire lifetime in healthy aged subjects: an fMRI study. Cereb. Cortex. 17, 24532467

Wan, C.Y., Schlaug, G., 2010. Music making as a tool for promoting brain plasticity across the life span. Neuroscientist. 16, 566-577

White, E.J., Hutka, S.A., Wiliams, L.J. Moreno, S. 2013. Learning, neural plasticity and sensitive periods: implications for language acquisition, music training and transfer across the lifespan. Front. Syst. Neurosci. Nov 20;7:90 doi: 10.3389/fnsys.2013.00090

Zatorre, R.J., Fields, R.D., Johansen-Berg, H., 2012. Plasticity in gray and white: neuroimaging changes in brain structure during learning. Nat Neurosci.15, 528-536

Zatorre, R.J., Halpern, A.R., Bouffard, M., 2010.Mental reversal of imagined melodies: a role for the posterior parietal cortex. J Cognitive Neurosci.22, 775-789 